\title{
CHIKABA, LA PRIMERA MONJA NEGRA EN EL SISTEMA ESCLAVISTA FINISECULAR ESPAÑOL DEL SIGLO XVII
}

\author{
POR \\ ELVIRA M. MELIÁN \\ Doctora en Medicina y Cirugía por la Universidad Autónoma de Madrid. \\ Máster en Ciencias Históricas, Universidad Rey Juan Carlos.
}

\section{RESUMEN}

Sor Teresa Juliana de Santo Domingo llegó a España procedente de la Costa del Oro en 1686. Supuesta princesa en su tierra natal, Carlos II delegó su propiedad en los Marqueses de Mancera. En su casa viviría como esclava entre los 10 y los 27 años, para luego ingresar en el convento de la Penitencia de Salamanca hasta su muerte en 1748. Este trabajo rescata la memoria de quién es hoy celebrada como la primera «religiosa» negra admitida en un convento de clausura español, la primera escritora afro hispánica en lengua castellana, y la primera negra «española» envuelta en un proceso de beatificación.

PALABRAS CLAVE: esclavitud negra, costa del oro, clausura femenina, españa siglo XVII-XVIII, marqués de Mancera

\section{CHIKABA, THE FIRST BLACK NUN IN THE SPANISH SLAVERY SYSTEM OF THE FINAL XVIITH CENTURY.}

\section{ABSTRACT}

Teresa Juliana de Santo Domingo reached Spain from the Gold Coast in 1686. Considered as princess in her natal country Charles II offered her to Marqués de Mancera. She lived in his house as slave from 10 to 27, when she entered as nun in a Salamanca cloister until her death in 1748. This article bring to the reader the memory of whom is regarded today as the first black nun in a Spanish cloister, the first afro-Hispanic black writer in castellan and the first «Spanish» black involved in a beatification process. 
KEY WORDS: black slavery, gold coast, female cloisters, women's, spain XVIIXVIII century: marqués de Mancera

Recibido/Received 02-12-2010

Aceptado/Accepted 06-02-1012

Teresa Juliana de Santo Domingo, Chikaba, nació en la Mina Baja del Oro hacia 1676 y allí vivió, presuntamente como princesa, hasta que fue apresada y trasladada a España. Su hipotética sangre real la llevó hasta la corte de Carlos II quien la cedió a Antonio Sebastián de Toledo, $2^{\circ}$ Marqués de Mancera. Este hombre, grande de España y virrey de Méjico durante 9 años, ${ }^{1}$ era célebre por haber prohijado a Sor Juana Inés de la Cruz. ${ }^{2}$ Desde los 10 a los 27 años sería una esclava en el palacio de los Marqueses de Mancera, y desde los 27 hasta su muerte a los 74 años una monja de clausura en Salamanca. Víctima de un singular destino Chikaba es celebrada hoy como la primera negra admitida como religiosa en un convento de clausura español ${ }^{3}$ y como la primera escritora afro hispánica en lengua castellana. ${ }^{4}$ Pese a ello y a ser protagonista de un proceso en curso de beatificación ${ }^{5}$ su persona permanece en la oscuridad, si exceptuamos la hagiografía publicada por Juan Carlos Paniagua en 1752, a los 4 años de su muerte. ${ }^{6}$ En este trabajo pretendemos rescatar brevemente su memoria mediante un doble ejercicio intelectual; por un lado entretejer su vida con los hechos históricos que la envolvieron en España y en su Mina del Oro natal; por otro analizar críticamente los escasos textos conservados de/sobre ella destilándolos en lo posible de la servidumbre ideológica de sus biógrafos.

\footnotetext{
${ }^{1}$ Hanke, L. 1978. Méjico: los virreyes españoles en América durante el gobierno de la Casa de Austria, tomo V. Madrid: Biblioteca de Autores Españoles.

${ }^{2}$ Paz, O. 1983. Sor Juana Inés de la Cruz o Las trampas de la fe. Méjico: Fondo de Cultura Económica.

3 Velázquez, M. L. 2004. La mujer de origen africano en la capital novohispana, siglos XVII y XVIII. Méjico: UNAM. En esta referencia se documentan monjas negras, lo cual podría explicar la entrada de Chikaba en un convento inducida por Mancera, conocedor directo de este mundo.

${ }^{4}$ Fra Molinero, B. 1999. La primera escritora afro hispánica. Chikaba o Sor Teresa Juliana de Santo Domingo, www.abacus.bates.edu/ bframoli/pagina/chicaba.htlm.

${ }^{5}$ Maeso, M. E. 2004. Sor Teresa Chikaba, princesa, esclava y monja. Salamanca: Biblioteca Dominicana. En 2004 se promovió el proceso de su beatificación, aún no resuelto, por la orden de Predicadores de la Asamblea Africana de Sudáfrica, sin que el color de su piel parezca ajeno al mismo.

${ }^{6}$ Paniagua, J. C. 1752. Compendio de la vida ejemplar de la venerable madre Sor Teresa Juliana de Santo Domingo, tercera profesa en el convento de Santa María Magdalena, Vulgo de la Penitencia. Salamanca.

Existe una edición reciente de la obra de Paniagua Compendio de la vida ejemplar de la venerable madre Sor Teresa Juliana de Santo Domingo. 2004. Salamanca: Dominicas Dueñas.
} 


\section{ÁFrICA: EL SISTEMA ESCLAVISTA EN LA COSTA DEL ORO DURANTE EL SIGLO XVII}

La Costa del Oro debe su nombre a la admiración de los primeros colonizadores portugueses del siglo XV por la abundancia de este metal en sus minas y en las arenas de los ríos. ${ }^{7}$ Dentro de esta costa la Mina Baja del Oro incluía lo que hoy es el territorio entre Assinie en Costa de Marfil y el río Volta en Ghana del este, todo ello denominado Guinea en los mapas del siglo XVII. Gracias a las exhaustivas descripciones de Jean Barbot, quien viajó por África Oriental entre 1678 y 1712, sabemos que por entonces abrazaba un espacio de 110 leguas de extensión y 400 de circunferencia entre los ríos Costa y Volta, e incluía 42 reinos (13 marítimos y 29 no marítimos) desplegados desde la costa hasta 60 millas en el interior. ${ }^{8}$

Tras más de dos siglos de colonización cuando Chikaba vió la luz, hacia 1676 , la tierra estaba sembrada de fortalezas y factorías para el tráfico de marfil y oro, ${ }^{9}$ pero la «calidad» de los esclavos los había convertido en el más valioso bien de exportación. Desde la década de 1670 la trata esclavista estaba prácticamente en manos de los holandeses, y los dueños de asientos tenían que apoyarse en ellos para la extracción de esclavos. ${ }^{10}$ La monarquía española carecía de capacidad para realizar por sí misma el tráfico en número significativo y aprovechaba el monopolio portugués, parte del Imperio entre 1580 y 1640. La Casa de la Contratación de Sevilla jugará un papel central en este trato de favor, concediendo sus contratos primero a los mercaderes portugueses y, a partir de 1685, al holandés Baltasar Coymans. ${ }^{11}$

En 1686 Chikaba se sumaría a los más de 600.000 negros exportados por los europeos de los puertos africanos entre 1675 y $1700 . .^{12}$ Ese mismo año en nuestras fronteras el Consejo de Indias incluía a instancias de Carlos II, en un documento con otros fines, dictámenes sobre la conveniencia y moralidad del tráfico esclavista. Se justificaban la conveniencia por las necesidades del Imperio y la legalidad con un sofisma fundamentado en la ausencia de oposición del estamento eclesiástico y el papado. ${ }^{13}$ Aunque Tomás Vitoria y la Escuela de Sala-

\footnotetext{
7 Vogt, J. 1998. Portuguese rule on the Gold Coast 1469-1682. New York: University Georgia Press.

${ }^{8}$ Barbot, J.1992 (re-edición). Barbot on Guinea: the writtings of Jean Barbot on West Africa 1678-1712. Londres: Halkluyt Society (175-176).

${ }^{9}$ Thomas, H. 1997. The slave trade. New York: Simon \& Shuster Paperbacks.

${ }^{10}$ Goslinga, C. 1985. The Dutch in the caribbean and in the Guianas 1680-1791. Assen: Van Gorcum and Co.

${ }^{11}$ Entre 1670 y 1675 el asiento correspondió a dos hombres de negocio portugueses, Antonio García y Sebastián de Silíceo; al Consulado de Sevilla; y a Juan Barroso, comerciante independiente de Sevilla. En 1685 fue adjudicado a Baltasar Coymans, no sin problemas con el Papa por ser éste un protestante.

12 Prat Manix, D. 1968. Historia de la trata de negros. Madrid: Alianza Editorial.

13 Thomas, H. 1997: 216.
} 
manca habían sentado los principios del derecho internacional negando la esclavitud natural aristotélica quedaban muchos resquicios para mantener la esclavitud legal y/o administrativa. ${ }^{14}$ Pensadores como Mercado, Albornoz y en especial Luís de Molina consideraban ilícito el comercio de negros sobre la base de la falta de garantías en la trata portuguesa desde su origen, ${ }^{15}$ pero no se cuestionaba la legitimidad de un fenómeno que llevaba siglos instalado en ambas culturas peninsulares, la católica y la musulmana; recordemos si no las amargas quejas de los moriscos cuando en 1567 Felipe II les prohíbe tener esclavos negros. ${ }^{16}$

Con todo la presencia de esclavos negros bozales en la península había descendido significativamente en la segunda mitad del siglo XVII. ${ }^{17}$ Los registros muestran sobre todo mujeres en el servicio doméstico y en los conventos, y hombres en el artesanado o ayudando a sus dueños en algunos gremios. Las causas del descenso han sido enumeradas por Domínguez Ortiz: mala reproducción en cautividad, facilidades para el rescate y liberación de los esclavos, encarecimiento de la compra tras la revolución de Portugal, y extenuantes confiscaciones generales para los galeones de la Corona. ${ }^{18}$

Antes de adentrarnos en la experiencia peninsular de la esclava bautizada como Teresa Juliana intentaremos hacer un reconocimiento histórico, siempre marginal, sobre su posible origen. Las concordancias entre la hagiografía de Paniagua y un relato publicado en Paris en 1714 permiten especular que pudo nacer en Ifsini, pequeño reino marítimo en lo que hoy es la frontera entre Ghana y Costa de Marfil. ${ }^{19} \mathrm{El}$ relato francés cuenta los viajes que realizara a este lugar entre 1687 y 1701 Loyer, prefecto de las misiones en la costa de Guinea. En él se glosa como los dominicos franceses llegaron a la zona en 1687 y regresaron a Francia con un esclavo que pretendía ser heredero del rey de Ifsini. Este

14 Mercado, T. 1975. Suma de tratos y contratos. Madrid: Restitutio Sierra Bravo (original de 1571).

${ }^{15}$ Gallego, J. A. y García Añoveras, J. M. 2002. La Iglesia y la esclavitud de los negros. Madrid: Eunsa.

${ }^{16}$ Domínguez Ortiz, A. 1978. Historia de los moriscos: vida y tragedia de una minoría. Madrid: Biblioteca de la Revista de Occidente.

${ }^{17}$ López Cortés, J. L. 1989. La esclavitud negra en la España peninsular del siglo XVI. Salamanca: Universidad de Salamanca.

${ }^{18}$ Domínguez Ortiz, A. 2003. La esclavitud en Castilla en la Edad Moderna. Granada: Comares.

19 Terracina, M. Historia General de los Viages. 1765. «Viage de Loyer a Ifsini en la Costa de Oro»: tomo V, libro VIII, capítulo III: 1-51. Madrid: Imprenta de Juan Antonio Lozano. La Historia General de los Viajes consta de 5 volúmenes, traducidos inicialmente del inglés al francés por el abate Antonio Francisco Prevost, y de éste al castellano por Miguel Terracina. El texto de Loyer data de 1714. En el original inglés se habla de Ifsiny. El mismo lugar es llamado por Jean Barbot Ifseny, Assinie o Assiny. Hoy en día nos encontramos con Assenie (cerca de la frontera de Ghana pero en Costa de Marfil) e Isseny Grande (Half Assini) en Ghana cerca de Costa de Marfil. 
príncipe fue protegido por Luís XIV hasta que en abril de 1701 inició con honores el regreso a su país como colaborador con Francia. Aniaba, así se llamaba, resultó ser un impostor que incluso llegó a colaborar con los holandeses, sus acérrimos enemigos. La historia fue recogida por varios medios de la época, como el periódico El Mercurio de Europa, impreso en París en 1701, y es mencionada por el propio Loyer. ${ }^{20}$

Por su parte en su hagiografía Paniagua relata cómo en 1701 Juan Francisco, tío carnal de la esclava y también príncipe de la Mina Baja del Oro, retorna a su tierra desde la corte de Luís XIV para intermediar entre franceses y compatriotas. Es recibido en casa de los Mancera y solicita contraer matrimonio con su sobrina para volver ambos a África. Obviamente Chikaba lo rechazará impulsada por su fervor religioso. Se tratase o no del mismo personaje lo cierto es que en 1701 existían excelentes relaciones entre ambos países tras décadas de enfrentamiento, pues muerto Carlos II sin descendencia reinaba en España Felipe V, nieto de Luís XIV.

Los paralelismos geográficos y sociológicos entre las crónicas de Ifsini y el texto de Paniagua sugieren que o bien el sacerdote plagió el texto francés o bien Chikaba procedía de la zona. La descripción de la tierra y su costa, recorrida por uno de los más hermosos ríos navegables de África y «tan baja que apenas se pudiera distinguir desde una legua, si los árboles que la guarnecen no la hicieran descubrir desde tres leguas de Mar»;21 la existencia de Grandes -algo así como nobles-, o la media de 2-3 hijos por pareja frente a la prolífica natalidad en reinos vecinos son directamente extrapolables. ${ }^{22}$ La personalidad de Chikaba es un reflejo especular de los atributos antropológicos de las mujeres de Ifsini: presumida y amiga de collares y alhajas; altiva, coqueta y embaucadora; aficionada al encarnado y a las cintas; lisonjeadora de los colonizadores blancos; creyente en una divinidad suprema y en la transfiguración de las almas, y profundamente fetichista. ${ }^{23} \mathrm{El}$ uso de fetiches constituye tal vez la analogía más llamativa pues Loyer y Paniagua describen de forma específica su empleo para invocar la lluvia y para protegerse/ganar una guerra. Sólo que en África los fetiches serán cubos vacíos o puñales/sables, ${ }^{24}$ mientras que Chikaba utiliza estampas religiosas..$^{25} \mathrm{La}$ dependencia psicológica que la esclava ten-

\footnotetext{
20 Ídem: 20.

21 Ídem: 21.

${ }^{22}$ Ibídem. «Descripción de Guinea: Costa de Oro»: tomo V, libro IX, capítulo IV-V: 272-376.

${ }^{23}$ Ibídem. «Negros de la Costa de Oro»: tomo V, libro IX, capítulo VII: 379-417.

${ }^{24}$ Ibídem. «Viage de Loyer a Ifsini en la Costa de Oro»: tomo V, libro VIII, capítulo III: 45.

25 Paniagua J. L .1752:95.
} 
drá de estos objetos es señalada por su biógrafo como una remarcada característica de su personalidad. ${ }^{26}$

En África la niña tratará con comerciantes y traficantes blancos y el nombre de dos de sus hermanos, Juachipiter y Joachin, ambos tomados de los europeos, ilustran el ambiente que frecuentó. Es probable que fuera parcialmente cristianizada, y ello explicaría su temprana afición a las ilustraciones religiosas. Hasta los 8-9 años los niños vivían ociosos y libres en el campo pero a partir de entonces las niñas de Ifsini se consideraban en edad de emparejarse y todos sus movimientos se centraban en agradar a los blancos. Chikaba tenía 10 años al ser capturada pero aseguraba que se casaría con un blanco y describía a su secuestrador como un «blanco y gallardo joven». La forma habitual de adquirir reputación de riqueza para atraer a los europeos era cubrirse de brazaletes y cadenas en piernas y brazos. Capturada en estas condiciones no resulta extraño que la niña fingiera sangre real, recurso habitual en la zona para engañar a los tratantes. Bosman ${ }^{27}$ y el propio Loyer hablan de otros esclavos que engañaron durante años a los franceses sobre dicha premisa. En nuestro país ha sido publicado recientemente un caso similar, recogido de la correspondencia del tercer Conde de Fernán Núñez, Francisco de los Ríos y Córdoba. Un teórico príncipe africano de la Mina del Oro, Osquere Osinu, fue vendido como esclavo en 1688. Como ocurriera con Chikaba, Carlos II tuvo conocimiento de su existencia, lo trajo a la Corte y lo reasentó con una familia de la nobleza para su apadrinamiento. El supuesto príncipe, bautizado como Francisco Rey de Mina, terminaría generando una amplia controversia en la corte sobre la falacia de su origen real. ${ }^{28}$

Es dudoso que Chikaba fuese vendida a los tratantes por su hermano, pero creíble que fuera bautizada como Teresa en Santo Tomé, donde se llevaban a cabo ceremonias masivas como práctica habitual entre portugueses y españoles. El estoicismo de los negros frente a la muerte y su certeza de que volvían a su tierra al morir los hacía particularmente peligrosos en alta mar pues se arrojaban por la borda sin el más mínimo temor. ${ }^{29}$ Salvar el alma de estos paganos

\footnotetext{
${ }^{26}$ Paniagua es recurrente sobre el fervor y/o dependencia de Chikaba hacia imágenes (Ídem:18) y estampas religiosas. Así cuando Mancera reparte estampas del Cristo con la cruz a cuestas y no le da una «triste estaba Teresa al carecer de prenda, para sí tan estimada, ahunque aliviaba su dolor, comtemplarse a esfuerzos de su humildad; indigna de posseerla; callaba, y sufria, pero no se aquietaba» (Ídem: 35)

${ }^{27}$ Bosman, W. 1967. A new and accurate description of the Gold, the Slave, and the Ivory Coast. London: Facsimile ed, Frank Cass (original de 1705).

${ }^{28}$ Bouza, F. 2005. «La correspondencia del hombre práctico. Los usos epistolares de la nobleza española del Siglo de Oro a través de seis años de cartas del Tercer Conde de Fernán Núñez (16791684)», Cuadernos de Historia Moderna IV: 129-154.

${ }^{29}$ Barbot, J. 1992: 639.
} 
tranquilizaba las conciencias antes de emprender un viaje transatlántico de incierto final..$^{30}$ No faltaron en España quienes cuestionaron la validez de este bautismo como Pedro de Castro y Quiñones, arzobispo de Sevilla, quien tras un minucioso estudio de las condiciones del mismo en origen publicaría un edicto en 1614 para repetir en España el bautizo de numerosos esclavos procedentes de la Costa del Oro. 31

Bajo un barniz místico Paniagua encarna en Chikaba todos los tópicos sobre los barcos negreros: la famosa «melancolía fija» causa de tantas muertes en los cargamentos de esclavos por rechazo del sustento mínimo, el intento de lanzarse por la borda, los riesgos derivados de tornados y terroríficas tormentas. ${ }^{32}$ Todo ello durante un viaje desde Santo Tomé a Sevilla que, dependiendo de los vientos, duraba en 1686 una media de ocho a diez días.

\section{ESPAÑA: LA ESCLAVITUD NEGRA PENINSULAR EN LA EDAD MODERNA}

\section{1, Teresa Juliana y los Marqueses de Mancera}

Dentro del reducido consumo interior Sevilla era la ciudad con más tradición de compraventa de esclavos y eran asiduas las subastas mediante anuncios públicos en las calles. ${ }^{33} \mathrm{La}$ adquisición se realizaba fundamentalmente por la nobleza, y los hoy anónimos primeros propietarios pudieron comprar esta niña negra para el trabajo doméstico. ${ }^{34}$ Desconocemos las vías que llevaron a la cesión de Chikaba a Carlos II, aunque las presunciones sobre su origen debieron influir. Con frecuencia el esclavo era sometido a compraventa una vez adquirido, no siendo excepcional regalarlo a la Corona para ganarse el favor real.

Carlos II sabía que el Marqués de Mancera «gustaba de los extranjeros, efecto del compasivo amor con que alivió, y socorrió quanto Virrey a los Indios». ${ }^{35}$ Durante su estancia en Méjico había acogido a Juana Inés de la Cruz desde sus 16 a sus 20 años, y jamás ocultaría su admiración por las dotes e inteligencia de la mejicana. Admiración correspondida por la poeta en especial hacia la primera marquesa de Mancera, Leonor Carreto, fallecida súbitamente cuando regresaban a España en 1674.

\footnotetext{
30 Sandoval, A. 1987. Un tratado sobre la esclavitud. Madrid: Alianza Universidad (original de 1627).

31 Ídem.

32 Barbot, J. 1992.

${ }^{33}$ Núñez Roldán, F. 2004. La vida cotidiana en la Sevilla del Siglo de Oro. Sevilla: Silex.

34 Castro, A. 1892. «De la esclavitud en España». La España Moderna año IV, XXXVIIIn: 128-149.

35 Paniagua J. L, 1752:19.
} 
Mancera, consejero de estado de Carlos II tras la muerte de Juan de Austria, poderoso y longevo -llegaría a vivir 104 años- manifestaría abiertamente su visión de los negros bozales como idóneos para la esclavitud «dada su condición dócil y servil», 36 recordando notoriamente al primer Bartolomé de las Casas. Hombre de su época armonizaba la piedad cristiana hacia seres bautizados e infelices por naturaleza con su explotación. Cuando Juliana Teresa Portocarrero Meneses, segunda Marquesa de Mancera, se encuentra con una esclava negra de carácter vivo y vehemente estas contradicciones afloran abiertamente. Ante la más mínima protesta por parte resto de los siervos los marqueses,

«(...) se privaron de tener a Teresa a comer a la mesa y a su lado: y ocultando su cariño se portaron delante de ella de otro modo; que aunque afable y cariñoso hubiera hecho impresión en otro pecho verse tratar de repente como criada quien poco antes se tenía en lugar de hija (...)».37

Mancera era proclive a pedir el consejo de hombres prestigiosos para definir la naturaleza última de las habilidades de sus «adoptadas». Así hizo en Méjico con Juana Inés y así hará con Teresa Juliana, pero aquí terminan las analogías. $\mathrm{El}$ «comité de evaluación» no puede ser más diferente: para la mejicana será un comité de excelencia, para la africana un comité inquisitorial. Su tenue margen de confianza sobre la naturaleza bondadosa de los negros desaparece en cuanto Teresa muestra signos de desequilibrio. ${ }^{38}$ El más destacado será su reacción cuando los marqueses son visitados por protestantes. Dominada por una especie de enloquecimiento chilla sin control, hasta obligarles a encerrarla preventivamente. Esta reacción sugiere que la niña debió sufrir algún tipo de vejación física antes o durante su captura. La ingente cantidad de abusos cometidos contra los esclavos por los traficantes holandeses en este territorio se ha descrito con profusión. ${ }^{39}$ Es altamente significativa una frase de Paniagua «siendo aún niña, celosa de su pureza, daba voces a los marqueses para que no tratasen con protestantes», 40 que bien podría explicar su obsesiva insistencia sobre lo «no contado» de la biografía de Teresa Juliana a lo largo de todo el texto.

Las autoridades reunidas para evaluar a Sor Juana Inés de la Cruz fueron,

\footnotetext{
${ }^{36}$ Hanke, L. ed. 1978: 14.

${ }^{37}$ Paniagua, J. C. 1752: 22.

${ }^{38}$ Martín Casares, A. 2000: «Cristianos, musulmanes y animistas en Granada: identidades religiosas y sincretismo cultural» en B. Ares Queija, y A. Stella, (coord.), Negros, mulatos y zambaigos. Derroteros africanos en los mundos ibéricos: 207-221. Paris: Centre National de la Recherche Scientifique (CNRS) y Sevilla: Escuela de Estudios Hispano-Americanos del CSIC.

${ }^{39}$ Postma, J. M. 2008. The Dutch in the Atlantic slave trade, 1600-1815. Cambridge: Cambridge University Press.

${ }^{40}$ Paniagua, J. C. 1752: 34.
} 
«cuantos hombres profesaban letras en la universidad y ciudad de Méjico (...) en número llegaban a 40 y en las profesiones era vario, como teólogos, escriturarios, filósofos, matemáticos, historiadores, poetas, humanistas (..... ${ }^{41}$

Las autoridades convocadas para enjuiciar a Chikaba son eclesiásticos que la someterán a exorcismos para establecer si las voces y aullidos que profiere ante los protestantes, o las ausencias que caracterizaban sus encierros, son atribuibles al maligno. Nada insólito, si recordamos que el propio Carlos II es un ejemplo hechicería política en los más altos rangos sociales ${ }^{42}$ Tras concluir que «es de Dios el espíritu» se decide entregar su vida a la clausura. A partir de ese momento irrumpen en escena una interminable saga de directores espirituales empecinados en transformar a esta excluida social en un modelo de reinserción religiosa de la época.

Amén de los sacerdotes que la instruyen para «la oración y la vida religio$s a »$ no existen datos fidedignos del resto de educación dada a Teresa Juliana. Mientras vive con los Marqueses tiene ayas para ilustrarla en «los ejercicio y habilidades femeninos» $y$ el que fuera capaz de escribir poesía, si bien toscamente, es algo inaudito para una esclava negra de la época. ${ }^{43} \mathrm{Al}$ parecer mantuvo una fluida y hoy extraviada correspondencia con Félix Álvarez de Córdova, con el que convivió durante aňos en casa de los Marqueses y que luego sería monje benito. ${ }^{44}$ Según Paniagua siempre tuvo «directores de los más sabios y ajustados», pero esta afirmación debe ser filtrada por su imponderado fervor religioso. En cualquier caso la esclava negra fue progresivamente instruida para el macilento y angosto sendero del claustro en el que entraría con 27 años en octubre de 1703, permaneciendo hasta su muerte en 1748.

\section{2, Sor Teresa Juliana de Santo Domingo o la «Negrita de la Penitencia»}

Ya en las Siete Partidas se contempla la profesión religiosa como causa para la liberación de los esclavos y el testamento de Juliana Teresa Portocarrero es un ejemplo de «ahorramiento condicionado», es decir ligado a entrar a la vida religiosa. En él se

\footnotetext{
${ }^{41}$ Calleja, D. 1700. Fama y obras póstumas del Fénix de México, décima musa, poetisa americana, sor Juana Inés de la Cruz. Madrid: Imprenta de Manuel Ruiz de Murga.

${ }^{42}$ Rey Bueno, M. M. 1998. El hechizado. Medicina, alquimia y superstición en la corte de Carlos II. Madrid: Corona Borealis.

${ }^{43}$ López Cortés, J. L. 1989.

${ }^{44}$ Dos años menor que Teresa, al parecer convivieron durante 7 años en la Casa de los Marqueses. Su acta de profesión se encuentra en el Archivo Histórico Nacional, con el informe de limpieza de sangre, legajo 1036 de la Sección del Clero.
} 
«(...) manda a Teresa Juliana que hoy es mi criada y esclava y la dejo libre, en profesando de religiosa se le dé de mis bienes cincuenta ducados cada un an̆o para gastillos otras cosas que se le pueden ofrecer durante su vida». ${ }^{45}$

Las criadas en general y las negras en particular eran habituales en los conventos de mujeres, ${ }^{46}$ pues cuando una noble ingresaba podía llevar su esclava como dote manteniendo la propiedad o cediéndola al conjunto de la comunidad. ${ }^{47} \mathrm{Su}$ frecuencia indujo al ya referido Pedro de Castro a incluir en su edicto de 1614 sobre el bautismo de los negros un apartado específico para las negras esclavas en conventos. ${ }^{48}$ Otra cosa muy distinta era considerar a una negra como correligionaria religiosa, y el convento de la Magdalena o de La Penitencia no sería una excepción.

Fundado en 1548 para mujeres públicas arrepentidas la Magdalena era en el siglo XVII un convento tradicional de la Orden Tercera de las dominicas. ${ }^{49}$ La admisión de Teresa Juliana en una comunidad tan estricta sobre la «pureza de sangre» como la dominica sólo se justifica por la extrema penuria del convento y por la dote especialmente elevada que pagarán los Marqueses. ${ }^{50} \mathrm{El}$ propio obispo de Salamanca «con alguna repugnancia por el asunto» afirma que permite el ingreso por «ser de gran utilidad de la comunidad y aumento de las rentas de dicho convento». ${ }^{51}$ En el contrato de entrada de octubre de 1703, firmado por Teresa, se especifica que entra para

«servir a Dios en el convento con la cat<egoría no concretada de seglar o tercera beata con hábito» porque «paga 10.800 reales de vellón-toda su herencia- D. Andrés Bárcena como mayordomo del Marqués de Mancera y depositario de los bienes de la ya difunta Marquesa».52

\footnotetext{
${ }^{45}$ Protocolo del Escribano Francisco Lázaro Mayoral, no 13977. 10 Abril de 1703, Archivo Histórico Provincial de Madrid.

${ }^{46}$ Domínguez Ortiz, A. 1992. La sociedad española en el siglo XVII. Granada: Biblioteca de la Historia. CSIC; Morgado García, A. 2009. «El mercado de esclavos en el Cádiz de la Edad Moderna». Tiempos Modernos, 18: 1-25.

${ }^{47}$ Salinero, G. Maitres, domestiques et esclaves du Siecle d»Or. 2006. Madrid: Casa de Velázquez.

${ }^{48}$ Sandoval, A. 1987.

${ }^{49} \mathrm{Tal}$ vez la categoría fronteriza inicial del convento de la Magdalena o de la Penitencia, desaparecido en 1810, no fue ajena a la iniciativa de llevar a Chikaba al mismo. Una categoría fronteriza que compartieron muchos conventos «de la Penitencia», creados para redimir a grupos marginales de mujeres de la calle y luego reconvertidos según las necesidades. A ello hay que añadir que durante el siglo XVII el número de vocaciones había ido decreciendo exponencialmente.

50 Torres Sánchez, C. 1991. La clausura femenina en la Salamanca del siglo XVII. Salamanca: Universidad de Salamanca.

${ }^{51}$ Paniagua, J. C. 1752: 59.

52 Maeso, M. E. 2004: 40.
} 
Para vencer la resistencia interna de la comunidad se exime a las monjas de tratar a Sor Teresa Juliana como novicia, se la priva de directora espiritual, y se le vetan el coro, el refectorio y el dormitorio común. En realidad mantendrá siempre una ambigua condición de terciaria seglar con votos privados siendo tratada como inferior a todas las religiosas incluidas las legas. En la orden dominica las monjas de coro no realizaban los trabajos domésticos, en manos de las legas sin dote y de las criadas. Aunque en el contrato de admisión se especifica que no tiene obligación de servir a la comunidad lo cierto es que Sor Teresa Juliana ejercerá de esclava de las mismas ocupándose hasta el final de sus días de los trabajos más duros como cocinar, barrer, lavar o limpiar.

La africana poseía cierta ventaja frente a sus compañeras para sobrellevar las penurias físicas: en la Costa del Oro se había criado con una dieta escasa donde el pescado podrido era incluso un manjar, y dormido en un lecho bajo y duro formado por un jergón de guijarros y cuatro pajas. Pero sobrellevar la humillación espiritual la obligará a adherirse al enajenado misticismo de los siglos XVII-XVIII. ${ }^{53}$ A lo largo de su texto Paniagua atribuye a la Negrita de la Penitencia todos los estereotipos seculares de la desviación mística posteresiana: poderes curativos y milagrosos, ataques directos de «la infernal astucia» hacia su cuerpo y espíritu, premoniciones, visiones y locuciones. ${ }^{54}$ Sor Teresa Juliana personifica el recorrido desde el misticismo imitativo al ascetismo más extremo, pasando por la fabulación y la enajenación. Sus dolencias corporales permanentes y sus uniones místicas con Jesús ${ }^{55}$ cohabitan con la sublimación de todo tipo de sacrificios a favor de las demás monjas, en gran parte forzada por los confesores dominicos. Su condición de negra la hace idónea para «ejercitarla y probarla».

Pronto encontraremos roces entre la religiosa y sus directores espirituales, llegando ésta a plantearse renunciar a los mismos para «estar desasida de confesor». Es obligada a asumir contra su voluntad el cuidado de infieles, enfermas infecciosas «llenas de llagas y hedor» $\mathrm{y}$, por más de veinte años, de una demente/endemoniada hija de un contribuyente al mantenimiento del convento. Este último episodio ilustra la fuerza con qué persistía en los subconscientes colecti$v^{56}$ y de la propia Negrita la identificación entre enajenamiento, negritud y hechicería. ${ }^{57}$ Según Paniagua Teresa la «obligaba, la redujo a tal estado, impuso

\footnotetext{
53 Sánchez Lora, J. L. 2005. «Mujeres en religión» en I. Morant (coord.), Historia de las mujeres en España y América Latina II: 131-152, Madrid: Cátedra.

54 Ídem.

55 Paniagua, J. C. 1752: 102.

${ }^{56}$ Duque de Maura. 1900. Supersticiones de los siglos XVI y XVII y hechizos de Carlos II. Madrid: Saturnino Calleja.

${ }^{57}$ Martín Casares, A. 2000.
} 
su imperio, le producía miedo, la mataba de hambre, la desterraba o la controlaba». ${ }^{8}$ Mientras las otras profesas murmuraban que torturaba a su protegida la infeliz llegó a temerla tan intensamente que su inicial rebelión se tornó en una desesperada e inútil súplica por ser exclaustrada. Posiblemente sazonaba sus ancestrales nigromancias con jaculatorias y bendiciones, y en su extraviada correspondencia con Fray Félix de Córdova debió referirle sus experiencias con la endemoniada, al parecer hechizada con una manzana. La respuesta del benedictino es significativa «si ser hechizada es caso fuerte, y de poco, o ningún remedio; aún es peor que después de tanto tiempo, viva el causador, sin querer deshacer lo hecho». ${ }^{59}$ En este tiempo el exorcismo no dejaba de ser una forma ortodoxa de la denostada hechicería y el biógrafo confiere a su religiosa atributos propios de los saludadores como la curación mediante la imposición de manos, de saliva de su boca o de agua bendita, amén del don de la profecía. ${ }^{60}$

Únicamente se conserva una carta autógrafa de Sor Teresa, sin un contenido significativo, ${ }^{61}$ pero numerosos fragmentos de Paniagua aparecen entrecomillados como procedentes de su boca. De ellos se deduce el carácter incondicional de su sometimiento a la divinidad,

«Sentía dentro de mí corazón que le amase mucho, mucho; yo no sé, qué es amar a Dios, ni cómo darle gusto, sólo me parece a mí, que le gustará que en todo trate la verdad un corazón velador, siempre asido sólo a las cosas de su gloria, desterrando cosas terrenas en toda criatura, mirando sólo al creador y siendo sólo el señor suyo, alma, vida y corazón, sin dejar cosa libre fuera de su majestad: bien se conocerlo, mas el hacer falta....te quiero, te quiero, te quiero(...)» 62

Y en su único poema conservado el erotismo sublimado de toda mística hacia el amado focalizado en la figura de Jesucristo,

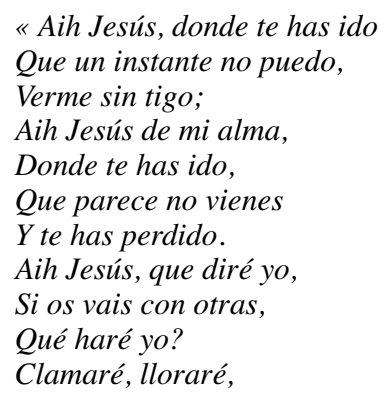

\footnotetext{
58 Paniagua, J. C. 1752: 86.

59 Paniagua, J. C. 1752: 84.

${ }^{60}$ Duque de Maura. 1900.

${ }^{61}$ Maeso, M. E. 2004: 46.

62 Paniagua, J. C. 1752: 100.
} 
Hasta ver a Dios,
Y si no, y si no,
Morir de amor.
Y ya lo digo,
Pues estoy tan sola
Que no has venido.
Y si estás con otra,
Yo ya lo he visto:
A Marta y María
Las has querido.
Aih Jesús, donde te
Hallaré yo,
Pues tan tonta me tiene
Quando te tengo;
A Dios, a Dios amor,
A Dios Señor,
A Dios corazón,
No más, no más, no más. ${ }^{63}$

Salvando su trascendencia como primera escritura afro hispánica en castellano el valor literario de este poema es muy escaso; ${ }^{64}$ pero no así su valor antropológico. En la Costa del Oro la poligamia era práctica habitual y el papel dominante de la primera mujer se asumía entre las posteriores. Observamos cómo esta mentalidad queda lejos para la ya españolizada negra, que vive a las «otras» como competidoras toleradas con mal disimulados celos. Con los años incluso la figura de María ha evolucionado, desde madre amantísima a conciencia represora, y desde ésta a incómoda Celestina en su relación con Jesucristo. Esta contradicción interna se refleja en la alternancia entre críticas veladas hacia María durante sueños/visiones y una machacona afirmación de su devoción mariana ante sus confesores,

«Señor, porque tengo algún temor, yo quiero de corazón a la Virgen Santísima; pero me parece quiero más a su Hijo Santísimo; no quisiera que la Virgen Santísima se quejara de mí, pues la debo mucho: lo digo para que V.R vea que se parece esto». ${ }^{65}$

Según Maeso durante sus años de clausura Sor Teresa Juliana tuvo «confidentes» con los cuales se comunicaba largos períodos de tiempo a través de las rejas y accedió al material habitual de lectura en los conventos dominicos como constituciones, evangelios o hagiografías de santos. Asimismo mantuvo corres-

\footnotetext{
63 Paniagua, J. C. 1752: 101.

${ }^{64}$ Ferrús Antón, B. 2008. «Sor Teresa Juliana de Santo Domingo, Chikaba, o escribir en la piel del otro», Cuadernos dieciochistas, 9:181-192.

65 Paniagua, J. C. 1752: 103.
} 
pondencia, al menos con Fray Félix de Córdova, y escribió asiduamente según las directrices de sus confesores, aunque este el material se ha extraviado.66 Considerando la génesis del libro, publicado por la comunidad dominicana con motivo de su propuesta de beatificación, creo que persisten las incógnitas sobre el íntimo grado de adaptación de la religiosa a su reclusión.

Gran parte de los episodios descritos por Paniagua son estereotipos de hagiografías tradicionales de la época sin valor objetivo. ${ }^{67}$ Pese a ello podemos «contemplar» ciertos episodios bien establecidos de su biografía como resultados secuenciales de la rebeldía e independencia de carácter que le imputaba. En este análisis encajarían: 1, su extravío y posterior secuestro en tierras africanas 2, la convocatoria del comité de eclesiásticos por Mancera para establecer si estaba poseída 3, la férrea custodia de sus confesores en la Penitencia temerosos de la autocrítica de sus visiones «los desprecié por pataratas» ${ }^{68}$ y de sus reincidentes dudas sobre el error de no haber vuelto a África «(...) cuanto mejor hubiera sido aceptar el convite de tu Tío? Irte con él a la Patria? (...) y no aquí en tierra extraña, desdeñada de quien acaso en tu tierra no admitirías en tu Casa para tu servicio» ${ }^{69} \mathrm{o}$, finalmente, la invitación para visitar su celda a dos frailes benedictinos en el curso de la más rígida Contrarreforma. Teresa los llevará con absoluta voluntariedad, como enfatiza Paniagua con cierto desconcierto, «se había de negar a los de fuera, ni mucho menos permitirlos, cuanto más buscarlos, para que viesen su Celda». ${ }^{70}$ Y ello en un momento de máxima censura sobre las voces femeninas de la iglesia católica. ${ }^{71}$

Tras largos años de clausura Sor Teresa muere en diciembre de 1748 abandonada a su suerte, como no podía ser de otra manera, «por disposición divina: el Principal ausente por obediencia: los demás algo tardos y perezosos, sin saber por qué, en asistir al alivio, y consuelo de Teresa, ni haber en el mucho cariño que le profesaban, más causa para el retiro que gustar a Dios». ${ }^{72}$ Es

\footnotetext{
${ }^{66}$ Maeso, M. E. 2004.

${ }^{67} \mathrm{La}$ obra de Paniagua se desarrolla en 42 capítulos sucesivos que van relatando las experiencias de su protagonista desde su niñez hasta su muerte según los cánones del género. Sin embargo hay elementos recurrentes propios de creencias de la Mina Baja del Oro, que escapan a los tópicos hagiográficos al uso y demuestran un entretejido entre ambos mundos del que no se pudo sustraer. Algunos ejemplos son 1, la naturaleza fetichista, animista y mágica que subyace permanentemente en su retrato de Chikaba 2, el encendido elogio de su capacidad para interaccionar con las almas en el purgatorio/submundo o 3, la descripción del diablo en forma de animales específicos (perros, bueyes). Sin contar con la insistencia en lo silenciado, que ya hemos comentado específicamente.

${ }^{68}$ Paniagua, J. C. $1752: 81$.

${ }^{69}$ Paniagua, J. C. $1752: 63$.

${ }^{70}$ Paniagua, J. C. 1752: 82.

${ }^{71}$ Reder Gadow, R. 2000. «Las voces silenciosas de los claustros de clausura». Cuadernos de Historia Moderna 25: 279-335.

72 Paniagua, J. C. 1752: 121.
} 
sepultada, contra sus deseos, en el «entierro común» del claustro del Convento de Santa María Magdalena. Posteriormente se trasladarán a otro convento dominicano de la ciudad, el de Santa María de las Dueñas, donde aún descansan.

\section{EPÍLOGO}

Aún está por determinar si Sor Teresa Juliana de Santo Domingo es finalmente beatificada. El esfuerzo en esta dirección lo inició el propio Paniagua en los últimos capítulos de su hagiografía y continúa en la actualidad, promovido por la Orden de Predicadores de la asamblea Africana de Sudáfrica. ${ }^{73}$

En su lecho de muerte la Negrita se lamenta «con verdad que bien quisiera salir de este destierro y pasar a la amada patria a descansar». ${ }^{74}$ Paniagua asumía que el destierro era la vida terrena y la patria la vida eterna. Pero tal vez el destierro era España y la patria aquél África azul a donde podría finalmente regresar. Allí el viejo Bossefou de sus ancestros, mucho más misericordioso que sus iguales europeos, examinaría su alma bajo la tierra. En caso de bondad le permitiría cruzar el río de la inmortalidad transmutada en un animal; en caso de maldad la dejaría ahogarse y desaparecer para siempre bajo las aguas. ${ }^{75}$ Es sencillo imaginar que Sor Teresa Juliana de Santo Domingo, Chikaba, no debió sentir temor ante este último tránsito hacia sus orígenes. Orígenes que acaso fueron siempre el íntimo refugio para una razón gradualmente perturbada por la infinidad de humillaciones y mortificaciones que sufrió.

\section{BiBLIOGRAFÍA}

Barbot, J.1992. Barbot on Guinea: the writtings of Jean Barbot on West Africa 1678-1712. Londres: Halkluyt Society (175-176).

Bosman, W. 1967. A new and accurate description of the Gold, the Slave, and the Ivory Coast. London: Facsimile ed, Frank Cass.

Bouza, F. 2005. «La correspondencia del hombre práctico. Los usos epistolares de la nobleza española del Siglo de Oro a través de seis años de cartas del Tercer Conde de Fernán Núñez (1679-1684)», Cuadernos de Historia Moderna IV: $129-154$.

\footnotetext{
${ }^{73}$ Maeso, M. E. 2004.

74 Paniagua, J. C. 1752: 118.

75 Terracina, M. 1765. «Viage de Loyer a Ifsini en la Costa de Oro».
} 
Calleja, D. 1700. Fama y obras póstumas del Fénix de México, décima musa, poetisa americana, sor Juana Inés de la Cruz. Madrid: Imprenta de Manuel Ruiz de Murga.

Castro, A. 1892. «De la esclavitud en España». La España Moderna año IV, XXXVIIIn: 128-149.

Domínguez Ortiz, A. 1978. Historia de los moriscos: vida y tragedia de una minoría. Madrid: Biblioteca de la Revista de Occidente.

Domínguez Ortiz, A. 1992. La sociedad española en el siglo XVII. Granada: Biblioteca de la Historia. CSIC.

Domínguez Ortiz, A. 2003. La esclavitud en Castilla en la Edad Moderna. Granada: Comares.

Duque de Maura. 1900. Supersticiones de los siglos XVI y XVII y hechizos de Carlos II. Madrid: Saturnino Calleja.

Ferrús Antón, B. 2008. «Sor Teresa Juliana de Santo Domingo, Chikaba, o escribir en la piel del otro», Cuadernos dieciochistas, 9:181-192.

Fra Molinero, B. 1999. La primera escritora afro hispánica. Chikaba o Sor Teresa Juliana de Santo Domingo, www.abacus.bates.edu/ bframoli/pagina/ chicaba.htlm.

Gallego, J.A y García Añoveras, J.M. 2002. La Iglesia y la esclavitud de los negros. Madrid: Eunsa.

Goslinga, C. 1985. The Dutch in the caribbean and in the Guianas 16801791. Assen: Van Gorcum and Co.

Hanke, L. 1978. Méjico: los virreyes españoles en América durante el gobierno de la Casa de Austria, tomo V. Madrid: Biblioteca de Autores Españoles.

López Cortés, J. L. 1989. La esclavitud negra en la España peninsular del siglo XVI. Salamanca: Universidad de Salamanca.

Maeso, M. E. 2004. Sor Teresa Chikaba, princesa, esclava y monja. Salamanca: Biblioteca Dominicana.

Martín Casares, A. 2000: «Cristianos, musulmanes y animistas en Granada: identidades religiosas y sincretismo cultural» en B. Ares Queija, y A. Stella (coord.), Negros, mulatos y zambaigos. Derroteros africanos en los mundos ibéricos: 207-221. Paris:Centre National de la Recherche Scientifique (CNRS) y Sevilla: Escuela de Estudios Hispano-Americanos del CSIC.

Mercado, T. 1975. Suma de tratos y contratos. Madrid: Restitutio Sierra Bravo.

Morgado García, A. 2009. «El mercado de esclavos en el Cádiz de la Edad Moderna». Tiempos Modernos, 18: 1-25. 
Núñez Roldán, F. 2004. La vida cotidiana en la Sevilla del Siglo de Oro. Sevilla: Silex.

Paniagua, J. C. 1752. Compendio de la vida ejemplar de la venerable madre Sor Teresa Juliana de Santo Domingo, tercera profesa en el convento de Santa María Magdalena, Vulgo de la Penitencia. Salamanca.

Paz, O. 1983. Sor Juana Inés de la Cruz o Las trampas de la fe. Méjico: Fondo de Cultura Económica.

Postma, J. M. 2008. The Dutch in the Atlantic slave trade, 1600-1815. Cambridge: Cambridge University Press.

Prat Manix, D. 1968. Historia de la trata de negros. Madrid: Alianza Editorial.

Reder Gadow, R. 2000. «Las voces silenciosas de los claustros de clausura». Cuadernos de Historia Moderna 25: 279-335.

Rey Bueno, M. M. 1998. El hechizado. Medicina, alquimia y superstición en la corte de Carlos II. Madrid: Corona Boreales.

Salinero, G. Maitres, domestiques et esclaves du Siecle d'Or. 2006. Madrid: Casa de Velázquez.

Sandoval, A. 1987. Un tratado sobre la esclavitud. Madrid: Alianza Universidad.

Sánchez Lora, J. L. 2005. «Mujeres en religión» en I. Morant (coord.), Historia de las mujeres en España y América Latina II: 131-152. Madrid: Cátedra.

Terracina, M. Historia General de los Viages. 1765. Madrid: Imprenta de Juan Antonio Lozano.

Thomas, H. 1997. The slave trade. New York: Simon \& Shuster Paperbacks.

Torres Sánchez, C. 1991. La clausura femenina en la Salamanca del siglo XVII. Salamanca: Universidad de Salamanca.

Velázquez, M. L. 2004. La mujer de origen africano en la capital novohispana, siglos XVII y XVIII. Méjico: UNAM.

Vogt, J. 1998. Portuguese rule on the Gold Coast 1469-1682. New York: University Georgia Press. 